\title{
A MATEMÁTICA NA FORMAÇÃO DO ENGENHEIRO DE PRODUÇÃO: VISÕES DE UM COORDENADOR DE CURSO, DE UM DOCENTE E DE SETE EGRESSOS
}

DOI: 10.37702/2175-957X.COBENGE.2021.3412

Fabiana Satie Tanno - fabiana.tanno@gmail.com

Pontifícia Universidade Católica de São Paulo

Rua Angaturama 494

04164-010 - São Paulo - SP

Laura Cristina Yasuoka Assad - laura.yasuoka@gmail.com

Pontifícia Universidade Católica de São Paulo

Rua Guairá 205

04142-020 - São Paulo - SP

Rafael Rodrigues Diniz Lacerda Pires - rdiniz02@outlook.com IMT

Rua Des. Olavo Lima Guimaraes 400

05101-310 - Sao Paulo - SP

Barbara Lutaif Bianchini - barbaralb@gmail.com

Pontifícia Universidade Católica de São Paulo

Rua Frei Vicente do Salvador 183

02019-000 - São Paulo - SP

Eloiza Gomes - eloiza@maua.br

IMT

Rua Manuel Figueiredo Landim 126

04693-130 - São Paulo - SP

Gabriel Loureiro de Lima - gloureirolima@gmail.com

Pontifícia Universidade Católica de São Paulo

Rua Bragança Paulista 41

13218-250 - Jundiaí - SP

Resumo: O objetivo deste artigo, subsidiado pela Teoria A Matemática no 
Contexto das Ciências (TMCC) e pela etapa consequente da Dipcing, uma metodologia de elaboração de currículos a ela atrelada, é compreender, a partir de dados coletados por meio de entrevistas semiestruturadas, quais as visões de um coordenador de curso, um docente e sete egressos da graduação em Engenharia de Produção acerca de cinco temáticas. São elas: a caracterização de um engenheiro de produção e seus principais setores de atuação; as percepções dos egressos, em suas épocas de estudantes, a respeito das disciplinas matemáticas presentes em seus cursos de graduação e as dificuldades nelas enfrentadas; 0 papel da Matemática na formação do engenheiro de produção e como essa ciência deveria ser abordada neste curso; o que é exigido, em relação à mobilização de conceitos matemáticos durante os cotidianos profissionais de engenheiros de produção em atuação em diferentes setores; e aspectos importantes da Matemática para o mercado de trabalho não contemplados na formação inicial do engenheiro de produção. Como um dos resultados da pesquisa, destaca-se que, na visão dos egressos, a Matemática estudada no ensino superior, embora na maioria das vezes não seja diretamente aplicada em seus cotidianos profissionais, Ihes possibilitaram o desenvolvimento de habilidades de pensamento, além de formação e atitude científica, crítica e analítica, que beneficiam o enfrentamento de situações relacionadas a diferentes conteúdos que são mais utilizados no cotidiano profissional e desenvolve um tipo de raciocínio que pode ser usufruído em todas áreas de atuação.

Palavras-chave: Engenharia de Produção. Papel da Matemática na formação. Egressos. Mobilização de conhecimentos matemáticos. Cotidiano profissional. 


\section{INTRODUÇÃO}

Durante muito tempo, conforme destaca Lima (2012), acreditou-se que o aluno que ingressa na universidade, por ter optado por uma carreira que lhe agradava, inserida em uma área de estudos de seu interesse, já estaria suficientemente motivado para aprender os conteúdos das disciplinas constituintes da grade curricular de seu curso de graduação e, portanto, bastava o professor ministrar suas aulas que o aluno aprenderia, não sendo necessárias grandes preocupações do ponto de vista didático. No entanto, com o passar do tempo e com a democratização do acesso à universidade, percebeu-se que mesmo no ensino superior seriam necessárias reflexões didáticas e pedagógicas. Uma das razões para isso é a diferença existente entre a Educação Básica e os cursos de graduação, o que faz com que essa transição, na maioria das vezes, não ocorra de maneira suave para os estudantes. Outro aspecto diz respeito às dificuldades inerentes aos próprios objetos de estudo do ensino superior aliadas à necessidade de os estudantes cursarem, nos primeiros semestres da graduação, disciplinas básicas que muitas vezes não são trabalhadas de forma vinculadas à área específica que, ao ingressar na universidade, escolheu para estudar. É o que ocorre, por exemplo, em muitos casos, com as disciplinas matemáticas em cursos de Engenharia.

A respeito especificamente das disciplinas matemáticas, uma vez que neste artigo nosso foco é tratar da Matemática na formação do Engenheiro de Produção, Lima et al. (2015, p.2), a partir das ideias de Howson et al. (1988), Torres et al. (1999) e Bizelli (2003), salientam que "cada vez mais as ciências demandam algum tipo de compreensão e raciocínio matemáticos (e) consequentemente, diferentes cursos de graduação passam a ter em seus currículos disciplinas matemáticas" e, conforme indicam diferentes pesquisas, estas continuam sendo algumas das principais responsáveis por reprovações e por altas taxas de evasão nos cursos superiores da área de Ciências Exatas, como o de Engenharia de Produção.

De acordo com Bizelli (2003), nesses cursos, em geral, tais disciplinas parecem apenas ter um papel a cumprir na matriz curricular, não sendo claro, para a maioria dos estudantes e mesmo dos docentes, as funções destas para a formação humana, cultural e técnica dos futuros profissionais das áreas nas quais tais disciplinas estão a serviço. Além disso, conforme salienta Simons (1988), como esses estudantes não escolheram a Matemática como seu principal campo de interesse e não têm, como já destacado, clareza a respeito do papel das disciplinas desta área para sua formação, acabam considerandoas apenas como obstáculos a serem superados.

Como salientado em Lima et al. (2015, p. 2), é preciso buscar a integração entre os professores das disciplinas matemáticas e aqueles das disciplinas específicas e "os docentes devem buscar alternativas [...] envolvendo-se em técnicas pedagógicas que apresentem os conteúdos de forma mais atrativa e correlacionada com aplicações práticas do cotidiano do futuro profissional, incluindo o uso da tecnologia, de oficinas e de laboratórios". Assim, é necessário repensar currículos de Matemática para cursos de Engenharia, e no caso específico em discussão neste artigo, de Engenharia de Produção, tendo como premissa a ideia de contextualização, uma vez que, como reforçam Bianchini et al. (2017), esse aspecto tem implicação direta na motivação do futuro engenheiro em estudar conceitos matemáticos.

A pesquisadora mexicana Patricia Camarena Gallardo também reforça que é necessário que um engenheiro "tenha uma forte formação em Matemática, porém em Matemática no contexto da Engenharia" (CAMARENA, 2010, p. 19) e tanto essa autora, 
quanto Alpers et al. (2013), destacam que a contextualização deve levar em consideração, em cada uma das diferentes habilitações de Engenharia, suas especificidades. Afinal, "sabe-se que a Engenharia é uma área bastante ampla [...] e, consequentemente, o enfoque à Matemática que se deve dar é diferente em cada habilitação considerada" (CAMARENA, 2010, p. 20).

Em vista disso, é necessário que se discuta os conceitos e objetivos específicos dessas disciplinas matemáticas no curso de Engenharia, particularmente em nosso estudo de Produção, e que se construa, urgentemente, uma identidade para elas. Para isso, devem ser elaborados currículos para essa habilitação de Engenharia contemplando temas matemáticos que efetivamente sejam importantes para a formação deste profissional. Além disso, deve-se buscar a integração entre a Matemática e as necessidades da Engenharia de Produção e propor nas disciplinas matemáticas uma abordagem alinhada a esse contexto profissional, de maneira a evidenciar ao estudante alguns dos usos que estes poderá fazer da Matemática em seu futuro cotidiano profissional ou, ainda que não utilize diretamente os conceitos estudados, perceba a importância destes para justificar determinadas técnicas que empregará com frequência. Ou seja, é importante formar profissionais capazes de utilizar a Matemática em contextos de Engenharia de Produção.

Essas são as considerações apresentadas que ratificam a importância desse tipo de investigação para as áreas de conhecimento da Educação Matemática no Ensino Superior, especialmente da Educação em Engenharia.

Salientando que, como afirmam, por exemplo, Cardella (2007), Alpers (2010) e Goold e Devitt (2012), ainda não há um número suficiente de investigações que permitam explicitar com clareza que tipo de uso engenheiros de produção fazem de conceitos matemáticos em seus cotidianos profissionais, o estudo de Iniciação Científica que estamos realizando com o objetivo de, a partir de entrevistas semiestruturadas com engenheiros de produção em exercício em diferentes setores de atuação, identificar quais conceitos matemáticos são por eles mobilizados em seus cotidianos profissionais, analisar de que forma se dá essa mobilização e refletir se, na percepção desses entrevistados, a abordagem dada a tais conceitos durante o curso de graduação que os formou esteve alinhada ao uso que fazem deles ao exercer suas funções profissionais, insere-se em uma temática de pesquisa importante. É pertinente inserir esse elemento nas discussões sobre currículos de Matemática para a Engenharia de Produção.

\section{FUNDAMENTAÇÃO TEÓRICA E METODOLÓGICA}

O referencial teórico que fundamenta a investigação que estamos realizando e que deu origem a este artigo é a Teoria A Matemática no Contexto das Ciências (TMCC), que começou a ser desenvolvida em 1982 no Instituto Politécnico Nacional (IPN) do México pela pesquisadora Patricia Camarena, especialmente para o Ensino Superior, tendo como foco principal cursos universitários que contemplam disciplinas matemáticas em seu currículo, mas que não visam à formação de matemáticos.

A TMCC é uma teoria que se desenvolve por meio de uma investigação científica que visa permitir ao professor universitário contribuir, a partir de sua prática docente, com uma formação integral do futuro profissional, buscando, ao invés de ministrar cursos de Matemática pela própria Matemática ou apenas porque aquele conteúdo faz parte do currículo proposto para determinada graduação, refletir, entre outros aspectos, a respeito do objetivo de se ensinar Matemática para aquele público-alvo, quais conteúdos ensinar, como ensiná-los de forma significativa, que proporção deve haver entre algoritmos e questões relacionadas ao formalismo matemático, que habilidades matemáticas devem ser 
desenvolvidas e de que maneira o ensino dessa ciência pode contribuir para o desenvolvimento das competências profissionais do estudante (CAMARENA 2011, 2013). O pressuposto filosófico educacional da TMCC é o de que, por meio de uma abordagem adequada das disciplinas matemáticas nos cursos de graduação, o aluno deve se tornar capaz de realizar a transferência dos conhecimentos matemáticos para aquelas áreas que os requerem.

A supracitada Teoria constitui-se por cinco fases, denominadas curricular, epistemológica, didática, cognitiva e docente. Nesta pesquisa em desenvolvimento, nos atemos à fase curricular, na qual tem-se como principal objetivo a elaboração de um currículo de Matemática que seja o mais adequado possível às necessidades de formação de um engenheiro de uma determinada habilitação de Engenharia. A construção deste currículo se dá, segundo Camarena $(2004,2011)$, com o auxílio de uma metodologia específica, denominada Dipcing (Diseño de programas de estúdios de matemáticas em carreras de ingeniería), composta por três etapas, sendo que cada uma delas fornece dados de naturezas distintas: conhecimentos prévios dos ingressantes nos cursos de Engenharia (etapa precedente); conhecimentos acerca das mobilizações de conhecimentos matemáticos nas disciplinas específicas de determinada habilitação de Engenharia (etapa central) e conhecimentos a respeito da mobilização de conceitos matemáticos por parte de engenheiros de determinada habilitação em seus cotidianos profissionais (etapa precedente).

A Dipcing que, de acordo com Camarena (2002, 2010), se desenvolveu em torno da premissa de que, em um curso de graduação que não vise à formação de matemáticos, as disciplinas de Matemática devem possuir programas objetivos, de tal forma que seja claro para o docente o porquê de cada tema matemático que consta do programa de dada disciplina estar presente em tal documento. Esta metodologia se fundamenta no paradigma educativo de que as disciplinas matemáticas deverão munir os graduandos de elementos e ferramentas que eles utilizarão nas disciplinas específicas de sua formação e também, posteriormente, em seus cotidianos profissionais.

Nesta pesquisa, recorreremos à etapa consequente da Dipcing. Realizamos entrevistas com Engenheiros de Produção efetivamente atuando como tais, com o objetivo de detectar como a Matemática é utilizada por esses profissionais em suas atividades laborais. Os resultados obtidos por meio desta etapa possibilitam, de acordo com Camarena (2002), uma melhor hierarquização em termos da importância que deve ser dada aos temas da Matemática em cada habilitação de Engenharia em foco, no caso, a de Produção. Considera-se a vinculação entre a Matemática presente na graduação em determinada habilitação de Engenharia e o que é mobilizado desta ciência no cotidiano de trabalho do Engenheiro, como o primeiro constructo teórico da etapa consequente da Dipcing.

Os dados coletados permitem evidenciar aqueles conteúdos utilizados pelos engenheiros em suas atividades profissionais e que estão presentes nos currículos das disciplinas universitárias que ele cursou. Explicitam também os conteúdos que não estão incluídos e que, se em um redirecionamento do programa de Matemática já em vigor ou no planejamento de um novo, realmente não puderem inseridos na graduação, por serem muito complexos ou específicos de determinados sub-ramos daquela Engenharia, poderão ser trabalhados em cursos de pós-graduação. A vinculação entre a graduação e a pósgraduação em determinada habilitação de Engenharia é o segundo constructo teórico proveniente dessa etapa da metodologia em tela.

O terceiro constructo teórico obtido por meio da etapa consequente é "a diferença entre a matemática escolar e a matemática de aplicação no campo profissional, fenômeno denominado transposição contextualizada" (CAMARENA, 2004, p. 4). A autora destaca 
que, da mesma forma que existe a transposição didática, definida por Chevallard (1991), como sendo o conjunto de processos necessários para transformar o saber científico em um saber a ensinar, há também a transposição contextualizada, que modifica o saber a ensinar transformando-o em um saber de aplicação.

Como já mencionamos na introdução deste artigo, na pesquisa de Iniciação Científica em desenvolvimento, utilizamos, para coleta de dados, entrevistas semiestruturadas que, por conta da relativa flexibilidade do instrumento, possibilita adequar a entrevista ao indivíduo, incentivando a espontaneidade, criando situações inesperadas e obtendo informações mais ricas e fecundas. Neste artigo, apresentamos e discutimos dados oriundos de entrevistas realizadas com sete egressos (na realidade seis egressos e um estudante que está no final de sua formação, mas já atuando na área) e também dados provenientes de entrevistas realizadas com dois professores, sendo um deles coordenador do curso de Engenharia de Produção e outro docente da disciplina de Introdução à Engenharia de Produção, ambos atuando na Instituição em que um dos autores deste artigo é aluno.

O objetivo central das pesquisas de Iniciação Científica que estão sendo realizadas pelos três estudantes (duas da Pontifícia Universidade Católica de São Paulo e um do Instituto Mauá de Tecnologia) sob a orientação dos docentes que também são autores deste artigo é compreender, por meio da visão dos egressos, como a Matemática é empregada na atuação profissional do engenheiro de Produção. No entanto, sentimos a necessidade de entrevistar também os dois docentes anteriormente mencionados, visando compreender, a partir da percepção do coordenador do curso, qual o perfil do egresso de uma graduação em Engenharia de Produção e, por meio dos conhecimentos do professor de Introdução à Engenharia de Produção, quais os principais setores de atuação deste profissional. Embora essas entrevistas com professores não tivessem como objetivo específico entender o uso que o engenheiro de produção faz da Matemática, contribuições também a respeito deste aspecto emergiram naturalmente nestes diálogos.

No Quadro 1 apresentado a seguir, explicitamos as formações, as respectivas instituições e os anos de conclusões destas formações, bem como as atuações, neste momento, na graduação em Engenharia de Produção dos dois professores entrevistados (aos quais nos referimos por PA e PB).

\begin{tabular}{|c|c|c|}
\hline \multicolumn{2}{|c|}{ Quadro 1 - Perfil acadêmico-profissional dos professores entrevistados } \\
\hline Professores & Formação & Atuação \\
\hline PA & Graduado (1987), Mestre (1999) e Doutor (2020) em & Coordenador do \\
& Univistração & $\begin{array}{c}\text { Curso de Engenharia } \\
\text { de Produção }\end{array}$ \\
\hline PB & $\begin{array}{c}\text { Graduado em Engenharia de Produção Mecânica (1994) } \\
\text { Universidade Federal de Santa Catarina }\end{array}$ & $\begin{array}{c}\text { Professor da } \\
\text { disciplina Introdução } \\
\text { à Engenharia de } \\
\text { Produção }\end{array}$ \\
\hline
\end{tabular}

Fonte: dados da pesquisa

O roteiro para as entrevistas semiestruturadas com PA e PB foi elaborado por um dos estudantes-pesquisadores supervisionado por uma das professoras autoras do artigo. O estudante também foi o responsável por realizar as entrevistas que, como já destacado, tiveram como focos principais delinear o perfil do egresso de um curso de Engenharia de Produção e os principais setores de atuação de um engenheiro desta habilitação.

Por meio do Quadro 2, apresentamos os dados relativos à instituição de formação dos sete egressos entrevistados (os quais denominaremos EA, EB, EC, ED, EE, EF e EG) e ao ano em que completaram suas graduações. As entrevistas, que foram conduzidas 
pelas estudantes, tiveram duração média de 30 minutos e, nesta ocasião, os entrevistados inicialmente assinaram o Termo de Consentimento Livre e Esclarecido (TCLE).

Quadro 2 - Instituição de formação e ano de conclusão do curso dos egressos entrevistados

\begin{tabular}{|c|c|c|}
\hline Egressos & Instituição de Formação & Ano de Conclusão do Curso \\
\hline EA & Instituto Federal de São Paulo (IFSP) & 2012 \\
\hline EB & Universidade Federal de São Carlos (UFSCar) & 2010 \\
\hline EC & Universidade Federal de São Carlos (UFSCar) & 2021, mas já atuando na área \\
\hline ED & Instituto Federal de São Paulo (IFSP) & 2019 \\
\hline$E E$ & Instituto Federal de São Paulo (IFSP) & 2013 \\
\hline EF & Universidade Federal de São Carlos (UFSCar) & 2020 \\
\hline EG & Fundação Hermínio Ometto (FHO) & 2019 \\
\hline
\end{tabular}

Fonte: dados da pesquisa

O roteiro para a realização destas entrevistas semiestruturadas foi elaborado pelas estudantes-pesquisadoras sob orientação dos professores da instituição em que essa Iniciação Científica é desenvolvida e que são também autores deste artigo, com base nos textos sobre a TMCC e a metodologia Dipcing. O primeiro bloco de questões diz respeito à trajetória acadêmica dos entrevistados como estudantes, os pontos de vista que tinham com relação às disciplinas matemáticas e as principais dificuldades nelas enfrentadas. As perguntas do segundo bloco focaram na vida profissional dos entrevistados quanto ao uso de conceitos matemáticos utilizados em seus cotidianos profissionais. No bloco final, questionamos quais sugestões os entrevistados dariam para possibilitar uma maior articulação, nos cursos e graduação, entre as disciplinas de Matemática e as situações correntes de suas profissões.

Todas as entrevistas foram audiogravadas, posteriormente transcritas e textualizadas. As textualizações foram lidas e destas leituras emergiram categorias temáticas, sendo que, neste artigo, apresentamos na sequência análises relacionadas aos seguintes temas: (C1) as visões dos entrevistados acerca da caracterização de um engenheiro de produção e de seus principais setores de atuação; (C2) as percepções dos egressos e as dificuldades enfrentadas nas disciplinas de Matemática presentes em suas formações; (C3) o papel da Matemática na formação do engenheiro de produção e como essa ciência deveria ser abordada no processo formativo deste profissional; (C4) as visões dos entrevistados acerca dos conceitos matemáticos utilizados pelo engenheiro de produção em sua prática; e (C5) aspectos importantes da Matemática para o mercado de trabalho não contemplados na formação inicial do engenheiro de produção.

\section{APRESENTAÇÃO DOS DADOS}

Nesta seção, apresentamos os dados obtidos por meio das entrevistas, que, na próxima seção, serão analisados sob a ótica da TMCC e dos constructos teóricos da etapa consequente da metodologia Dipcing para cada uma das cinco categorias temáticas anteriormente elencadas.

(C1) as visões dos entrevistados acerca da caracterização de um engenheiro de produção e de seus principais setores de atuação

De acordo com os entrevistados, o que caracteriza o engenheiro de produção é a flexibilidade e a versatilidade para poder atuar em diversas áreas. É um profissional estratégico e multifuncional que possui um bom raciocínio lógico, capaz de entender sobre diferentes áreas vinculadas a essa habilitação de Engenharia, com uma base de 
conhecimentos técnicos específicos. O engenheiro de produção é um profissional com capacidades para observar, analisar e atuar com uma visão macro, holística, funcional e logística em qualquer tipo de mercado, setor de empresa e fluxo de processos, tanto na indústria quanto no setor de serviços. O que destaca um engenheiro de produção é ter essa visão abrangente e geral, sendo capaz de se comunicar facilmente com todos.

De acordo com os dois professores entrevistados, o que caracteriza o profissional em destaque neste artigo são as habilidades desenvolvidas durante seu extenso e complexo curso. Este tem de ser, ao final de sua graduação, capaz de conceber (criar), projetar, desenvolver, implantar e gerenciar sistemas produtivos e logísticos inteligentes (bens e serviços). É importante ressaltar outras características essenciais deste profissional: a gestão de processos de fabricação, a atuação gerencial e o necessário desenvolvimento, na graduação, do raciocínio analítico e lógico. Além disso, muitas disciplinas do curso de Engenharia de Produção preparam o estudante para trabalhar em grupo, respeitando as opiniões diferentes, tornando-se mais maleável e com capacidade de liderança, que, na opinião dos entrevistados, é maior que a dos demais engenheiros.

Os conhecimentos matemáticos construídos durante sua graduação dão ao engenheiro de produção um lugar de potencial destaque no mercado financeiro, que requer um profissional que tenha raciocínio lógico e técnicas matemáticas apuradas, desenvolvidas a partir das disciplinas de algoritmos, álgebra e pesquisa operacional. Além deste setor, esse profissional pode atuar em outros diversos como o de transformação (indústria de manufatura mecânica automobilística), o comercial, a área de qualidade e, em empresas, como coordenador de fluxos, gestor de projetos ou analista de custos. Em última análise, o engenheiro de produção é um profissional que desempenha múltiplas funções, está sempre atento à dinâmica do mercado, com o objetivo de manter a posição competitiva da empresa e o controle da operação rentável.

(C2) as percepções dos egressos e as dificuldades enfrentadas nas disciplinas de Matemática presentes em suas formações

A formação matemática é considerada como uma parte importante da graduação de Engenharia de Produção. Para alguns entrevistados, na época da faculdade, essas disciplinas não eram as favoritas, e sim vistas unicamente como obstáculos a serem superados no ciclo básico. Atualmente, porém, estes percebem o valor e a importância da Matemática para o desenvolvimento profissional. Mesmo que os conceitos desta ciência não sejam diretamente aplicados em seus cotidianos profissionais, o estudo da Matemática é, na opinião dos egressos, importante para o desenvolvimento de seus raciocínios ágeis e de seus pensamentos analíticos o que, em suas visões, é oportunizado pelo processo árduo de resoluções de exercícios extensos.

Os egressos entrevistados destacaram que, em suas graduações, a maneira como a Matemática era abordada no ciclo básico distanciava o aluno dos primeiros anos do contexto de sua futura atuação profissional, o que ocasionava a não percepção, por parte do ingressante, de como o conteúdo que estava sendo estudado poderia vincular-se ao futuro cotidiano profissional, tornando-o, na visão de muitos alunos, irrelevante para sua futura carreira. Porém, outros salientaram que o ciclo básico poderia ser o local perfeito para aprendizagem acerca de como os conceitos dessas disciplinas relacionam-se com a vida profissional de um engenheiro de produção.

As principais dificuldades enfrentadas pelos egressos entrevistados durante as disciplinas matemáticas que cursaram na graduação estiveram relacionadas aos seguintes aspectos: (i) aos conhecimentos prévios insuficientes ocasionados por uma formação matemática frágil na Educação Básica; (ii) ao caráter abstrato da Matemática que, como destacam os depoentes não é algo palpável, e o ser humano tende a não acreditar naquilo que não vê, o que, em relação à Matemática resulta em uma necessidade de maior 
dedicação e aprofundamento nos estudos para compreender e aplicar seus conceitos; (iii) à já mencionada aparente distância entre o que estava sendo ensinado e sua aplicação no campo profissional; (iv) à ênfase, por vezes excessiva, dos professores em relação à linguagem matemática e ao simbolismo que, ao mesmo tempo os incentivava a comunicarse matematicamente de forma adequada, mas dificultava o entendimento do que estava sendo estudado; e (v) ao foco, em algumas disciplinas, muito voltado para a resolução bemsucedida de avaliações em detrimento da construção efetiva dos significados do que estava sendo trabalhado.

(C3) o papel da Matemática na formação do engenheiro de produção e como essa ciência deveria ser abordada no processo formativo deste profissional

Os engenheiros de produção veem como fundamental o papel da Matemática. Em suas visões, apesar da complexidade dos temas estudados nesta ciência, os problemas abordados nas disciplinas relativas à esta área os obrigam a pensar, analisar cuidadosamente os dados e tentar encontrar um caminho que os leve às soluções dos problemas, o que os ajuda a desenvolver o raciocínio lógico e o pensamento analítico dos futuros engenheiros. Os conhecimentos matemáticos, mesmo que indiretamente, proporcionam ao futuro engenheiro um alicerce sobre o qual ele poderá assentar outros conceitos continuamente aprendidos que são essenciais no mercado de trabalho e nas diferentes funções que poderá desempenhar. Como destaca um dos entrevistados, é fundamental que todo engenheiro de produção seja capaz de resolver problemas e desenvolver análises aprofundadas.

Os depoentes consideram que um aspecto central oportunizado pelo estudo da Matemática é que ela auxilia no desenvolvimento da autonomia, do autodidatismo, algo essencial ao futuro engenheiro, que precisará, em sua prática, identificar situações que demandem a aplicação de conceitos matemáticos, o enfrentamento de problemas não triviais e a desenvoltura em utilizar ferramentas técnicas como, por exemplo, na programação de sistemas.

Em relação a como a Matemática deveria ser abordada na formação inicial do engenheiro de produção, os entrevistados ressaltam a importância de: (i) os professores possibilitarem a construção sólida de conceitos; (ii) oportunizar o aprendizado acerca do contexto histórico da Matemática para a Engenharia e (iii) recorrer a projetos interdisciplinares com o objetivo de incentivar um maior engajamento dos alunos em suas aprendizagens. Salientam também que, há, em algumas disciplinas matemáticas um detalhamento desnecessário, em relação a alguns conceitos e que os momentos a eles destinados poderiam ser focados em outros assuntos considerados mais importantes no cotidiano profissional, como por exemplo, um aprofundamento em conhecimentos de Estatística e de Finanças Básicas, uma vez que a área financeira é um potencial campo de atuação do engenheiro de produção. Os egressos também comentam a respeito da necessidade de maior exploração, durante o curso, de ferramentas tecnológicas, como, por exemplo, funções mais avançadas do Excel.

(C4) as visões dos entrevistados acerca dos conceitos matemáticos utilizados pelo engenheiro de produção em sua prática

Elementos de algumas disciplinas matemáticas presentes na formação do engenheiro de produção, como, por exemplo, Cálculo Diferencial e Integral, Cálculo Numérico, Estatística, Álgebra Linear (em especial, o conceito de matriz), Finanças e Pesquisa Operacional, apesar de muitas vezes serem indiretamente utilizadas ao resolver diferentes situações por meio de ferramentas, como por exemplo o Excel, são essenciais como base para análise da otimização em uma distribuição de produtos, análise de dados de empresas e no mercado financeiro. 
O Engenheiro de Produção utiliza a Matemática no âmbito das seguintes atividades ou segmentos: maximização de investimentos, alocação de recursos, atratividade, tempos de produção, negociação, custos industriais, determinação de capacidade e volume de produção. Na área financeira, a Matemática é requerida em situações de: flutuação de ações, variabilidade de câmbio, aporte, desembolso e custeio.

$\mathrm{Na}$ visão de um dos professores entrevistados, os conhecimentos matemáticos auxiliam o engenheiro de produção no acompanhamento de processos, na aplicação, análise e interpretação de equações e requisitos técnicos e dimensionais de produtos físicos, químicos e mecânicos que asseguram a qualidade e a segurança de produtos, o que faz da Matemática um conhecimento essencial para que o engenheiro de produção possa dar uma opinião e tomar uma decisão a fim de melhorar a qualidade de um processo de maneira segura.

(C5) aspectos importantes da Matemática para o mercado de trabalho não contemplados na formação inicial do engenheiro de produção

Em geral, os entrevistados afirmam que o que aprenderam de Matemática na graduação foi além do que necessitam em seus cotidianos profissionais. No entanto, alguns fazem apontamentos a respeito de tópicos que poderiam ser contemplados na formação de todo engenheiro de produção e que, de alguma forma, estão relacionados à Matemática e que, ao menos nos cursos em que estes depoentes estudaram, não estavam presentes. Citam, por exemplo, Matemática Financeira e questões relacionadas a duas aplicações da Matemática bastante em voga atualmente: Ciência de Dados e Machine Learning.

\section{DISCUSSÃO DOS DADOS}

As visões reveladas pelos entrevistados em relação ao papel da Matemática na formação e na atuação profissional de um engenheiro de produção são consonantes às ideias de Camarena (2018) para quem as disciplinas matemáticas devem, na formação do futuro engenheiro, possibilitar sua formação integral e o desenvolvimento de competências matemáticas da profissão, relacionadas aos conhecimentos matemáticos, habilidades, atitudes e valores que deve ter um indivíduo de uma determinada área de atuação profissional. Um dos paradigmas sobre o qual se fundamenta a TMCC, o de que a Matemática, além de ferramenta de apoio ao futuro engenheiro deve servir a ele também como matéria formativa, revela-se de maneira bastante contundente no depoimento dos entrevistados que, em diferentes ocasiões, salientaram a importância das disciplinas matemáticas que cursaram para o desenvolvimento do raciocínio lógico, do pensamento analítico, da habilidade de resolver problemas etc. É nítido nas respostas dadas pelos entrevistados que tais disciplinas matemáticas, embora na maioria das vezes não tenham sido abordadas com foco em capacitá-los a aplicar o conhecimento matemático de forma interdisciplinar em suas futuras atividades profissionais, Ihes possibilitaram 0 desenvolvimento de habilidades de pensamento, além de formação e atitude científica, crítica e analítica.

As dificuldades vivenciadas pelos egressos entrevistados enquanto estudantes nas disciplinas matemáticas estão profundamente atreladas às problemáticas que visam ser enfrentadas por meio das reflexões inseridas na TMCC, especialmente: o caráter abstrato da Matemática e a aparente separação entre a Matemática e suas aplicações usualmente reforçada pela forma como as disciplinas matemáticas estão organizadas e são desenvolvidas nos cursos de Engenharia. Essa aparente desvinculação da Matemática e de suas áreas de aplicações acaba, como sinaliza Camarena (2010), muitas vezes 
desmotivando os futuros engenheiros a estudá-la e a perceberem apenas como obstáculos, desnecessários, a serem superados durante sua formação.

Em relação à maneira que os egressos concebem como uma alternativa mais apropriada para trabalhar a Matemática na formação do engenheiro de produção, esta vai ao encontro exatamente do que preconiza Camarena (1999) por meio da TMCC: os conteúdos matemáticos deveriam ser abordados de maneira significativa aos graduandos, de forma a capacitá-los para aplicar conhecimentos matemáticos na prática social de suas profissões. A menção feita por um dos entrevistados a respeito da necessidade, em sua visão, de serem abordados na formação do futuro engenheiro elementos da história da Matemática na Engenharia nos dá indícios de que a preocupação do depoente está atrelada à necessidade do graduando ter clareza a respeito do quão imbricados estiveram na história do desenvolvimento da Matemática e da Engenharia como campos de conhecimento, o estabelecimento de conceitos matemáticos e a resolução de problemas que hoje são clássicos nas diferentes habilitações de Engenharia.

Especificamente a respeito dos constructos teóricos inseridos na etapa consequente da metodologia Dipcing, os dados analisados nos permitem afirmar que:

- Ao menos nos setores de atuação de nossos entrevistados, não há uma vinculação direta entre a Matemática presente no curso de graduação em Engenharia de Produção e o que é mobilizado desta ciência no cotidiano de trabalho do engenheiro desta habilitação. Os conceitos matemáticos fundamentam situações que, em geral, enfrentam com o auxílio de ferramentas tecnológicas. O que os egressos evidenciam com muita clareza é o papel desempenhado pelo estudo da Matemática na graduação no desenvolvimento de formas de pensamento requeridas do engenheiro.

- A formação matemática oportunizada ao futuro engenheiro de produção em geral é mais do que suficiente para sua atuação profissional. No entanto, dependendo dos setores em que ele irá desempenhar suas funções, precisará estudar, por conta própria ou em pós-graduações, questões relacionadas à Matemática Financeira e a aplicações contemporâneas da Matemática, especialmente Ciência de Dados e Machine Learning.

- Em relação à maneira como os conceitos estudados nas disciplinas matemáticas são transpostos para o campo de atuação profissional do engenheiro de produção, os dados obtidos até o momento não nos permitem formular conclusões detalhadas, mas nossa percepção inicial é que ao serem aplicados nas situações profissionais, muitas vezes os objetos matemáticos tornam-se implícitos, já que são eles que dão subsídios para os funcionamentos de ferramentas às quais os engenheiros de produção recorrem, mas, na maioria das vezes, os profissionais não precisam mobilizá-los diretamente da maneira como os estudaram.

Passamos então a tecer algumas considerações finais relacionadas ao estudo realizado e às próximas etapas da pesquisa.

\section{CONSIDERAÇÕES FINAIS}

A partir da TMCC e da metodologia Dipcing, é possível trazer contribuições para o enfrentamento de problemas a respeito do papel da Matemática nos cursos de Engenharia, como por exemplo, a falta de motivação dos alunos, as altas taxas de evasão nos anos iniciais e os elevados índices de reprovação nas disciplinas de Matemática. Para isso, é fundamental que as matrizes curriculares dos cursos de graduação sejam repensadas e 
que se alinhem às necessidades do mundo no século $\mathrm{XXI}$, principalmente na área da Engenharia, que necessita estar cada vez mais em sintonia com os avanços tecnológicos. Assim, a Matemática deve ser trabalhada de forma contextualizada para contribuir com a formação do estudante, proporcionando a capacidade de construir conhecimentos de forma alinhada às necessidades específicas do futuro profissional.

A partir dos dados obtidos, foi possível concluir que as disciplinas básicas de Matemática, como Cálculo, Álgebra Linear, Geometria Analítica e Estatística são pouco utilizadas, de maneira direta, no cotidiano profissional do engenheiro de produção, mas exercem papel fundamental como desenvolvedoras do raciocínio lógico, base para muitas outras disciplinas e para o entendimento da resolução de problemas por meio de softwares. Além disso, é importante ressaltar que o Engenheiro de Produção, por exemplo, ao se tornar um gerente, acompanhará o processo como um todo e, com sua bagagem de conhecimentos matemáticos aliada aos conhecimentos técnicos específicos de sua área poderá tomar decisões mais coerentes e sensatas.

É preciso remodelar o currículo da graduação de cursos que não visam a formação de matemáticos, focando em uma maior integração entre as disciplinas matemáticas e as não matemáticas para deixá-las mais próximas ao cotidiano profissional de um Engenheiro de Produção. Como dizem Pinheiro e Burini (2006, p.160), "é necessário escolher situações-problema, para que os estudantes possam adequadamente desenvolver suas competências" e, de acordo com Araújo (2001, p. 58), "a autoatividade dos alunos constitui uma condição fundamental para a formação do trabalhador criativo e autônomo, capaz de se antecipar aos problemas e de mobilizar suas diferentes potencialidades e capacidades na concretização de suas atividades de trabalho".

Afinal, como diz Amaral et al. (2016, s.p.), o cenário contemporâneo "requer que as pessoas aprendam a aprender - e que se tornem capazes de identificar problemas, gerar ideias, ser autocríticos, resolver problemas e trabalhar com outras pessoas" e deve ser oferecida aos graduandos uma formação que promova a construção de conhecimentos profundos, como por exemplo, analisar um texto, argumentar tentando convencer alguém e resolver problemas de engenharia.

\section{REFERÊNCIAS}

AMARAL, S. F. et al. O ensino de Engenharia e competências para inovação: uma proposta inicial. In: XLIV Congresso Brasileiro de Educação em Engenharia - COBENGE, 2016. Natal RN, Anais do XLIV Congresso Brasileiro de Educação em Engenharia - COBENGE. Natal: ABENGE, 2016.

ALPERS, B. Methodological Reflections on Capturing the Mathematical Expertise of Engineers. Educational Interfaces between Mathematics and Industry, Lisbon, Portugal. pp. 41-51, 2010.

ALPERS, B et al. A Framework for Mathematics Curricula in Engineering Education. Report of the Mathematics Working Groups. Bruxelas: Sociedade Europeia de Ensino de Engenharia (SEFI), 2013.

ARAÚJO, R. M. de L. Desenvolvimento de competências profissionais: as incoerências de um discurso, 2001. Tese (Doutorado em Educação) - Universidade Federal de Minas Gerais, 2001.

BIANCHINI, B. L. et al. Competências matemáticas: perspectivas da SEFI e da MCC. Educação Matemática Pesquisa, São Paulo, v.19, n.1, p. 49-79, 2017.DOI: http://dx.doi.org/10.23925/19833156.2017v19i1p49-79. 
BIZELLI, M.H.S.S. A Matemática na formação do químico contemporâneo. 2003. Tese

(Doutorado em Educação Matemática) - Instituto de Geociências e Ciências Exatas, Universidade Estadual Paulista, Rio Claro, 2003.

CAMARENA, P. Reporte de proyecto de investigación titulado: Etapas de la matemática en el contexto de la ingeniería, con no. de registro: CGPI-IPN: 990413. Editorial ESIME-IPN, México, 1999.

Metodología curricular para las ciencias básicas en ingeniería. Revista Innovación Educativa, vol. 2, n. 10 e n. 11, pp. 22-28 e 4-12, 2002.

Constructos Teóricos de la Metodología Dipcing en el Área de la Matemática. Memorias: 3ํㅡㄹ Congreso Internacional de Ingeniería Electromecánica y de Sistemas. Ciudad de México: IPN ESIME - SEPI, 2004.

\section{Aportaciones de Investigación al Aprendizaje y Enseñanza de la Matemática en} Ingeniería, 2010. Disponível em:

http://www.ai.org.mx/ai/archivos/ingresos/camarenagallardo/dra._patricia_camarena_gallardo.pdf acesso em 15 de abril de 2021.

Concepción de competencias de las ciencias básicas em el níveluniversitário. In: DIPP, Adla J.; MACÍAS, Arturo B. (Org.). Competencias y Educación - miradas múltiples de una relación. México: Instituto Universitario Anglo Español A.C e Red Durango de Investigadores Educativos A.C., 2011, p. 88-118.

A treinta años de la teoría educativa "Matemática en el Contexto de las Ciencias".

Innovación Educativa, vol. 13, n. 62, p. 17-44, 2013.

Formación por competencias en las ciencias básicas de la ingeniería. Revista Brasileira de Ensino de Ciência e Tecnologia. Vol. 11, Núm. 2, p. 294-320, mai./ago., 2018.

CARDELLA, M. What Your Engineering Students Might Be Learning From Their Mathematics PreReqs (Beyond Integrals and Derivatives), ASEE/ IEEE Frontiers in Education Conference, Milwaukee, Wisconsin, pp. S4F1-S4F6, 2007.

CHEVALLARD, Y. La transposición didáctica. Del saber sabio al saber enseñado. Buenos Aires, Ar.: Aique Grupo Editor S. A, 1991.

GOOLD, E.; DEVITT, F. The role of mathematics in engineering practice and in the formation of engineers. Proceedings of 40th SEFI Annual Conference. Thessalonik, Greece, September, 2012.

HOWSON et al. Mathematics as a Service Subject. In: CLEMENTES, R. R. (Ed.). Selected Papers on the teaching of mathematics as a service subject. New York: Springer Verlag, 1988.

LIMA, G. L. A disciplina de Cálculo I do curso de Matemática na Universidade de São Paulo: um estudo de seu desenvolvimento, de 1934 a 1994. (Tese de doutorado em Educação Matemática). Pontifícia Universidade Católica de São Paulo, São Paulo, SP, 2012.

LIMA, G. L. de et al. Mobilização de conceitos de Cálculo na Engenharia Elétrica: um levantamento inicial. In: Anais do XLIII Congresso Brasileiro de Educação em Engenharia. São Bernardo do Campo - SP, UFABC, 2015.

PINHEIRO, A. C. F. B.; BURINI, E. R. V. Curso de engenharia por competências - uma proposta pedagógica para ambientes globalizados. In: XXXIV Congresso Brasileiro de Educação de Engenharia - COBENGE, 2006. Passo Fundo - RS, Anais do XLIV Congresso Brasileiro de Educação em Engenharia - COBENGE. Passo Fundo: ABENGE, 2006.

SIMONS, F. Teaching first-year students. In: CLEMENTS, R. R. (Ed). Selected papers on the teaching of mathematics as a servisse subject. New York: Springer Verlag, 1988.

TORRES, E. A. B. et al. A Importância da Geometria Descritiva na Engenharia, In: Anais do XXVII Congresso Brasileiro de Educação em Engenharia. Natal: UFRN, 1999. 


\title{
MATHEMATICS IN THE GRADUATION OF PRODUCTION ENGINEERING: VIEWS OF AN UNDERGRADUATE PROGRAM'S COORDINATOR, A TEACHER AND SEVEN EGRESSES
}

\begin{abstract}
The goal of this paper is to understand, based on data collected through semistructured interviews, what the views are of an undergraduate program's coordinator, a teacher and seven egresses of an undergraduate program of Production Engineering regarding five themes: the characterization of a production engineer and of his/her main sectors of activity; the egresses' perceptions on their student days related to the Mathematics courses present in their undergraduate programs and the difficulties they face; the role of Mathematics in the training of production engineers and how Mathematics should be addressed in this program; what is required regarding the mobilization of mathematical concepts during the daily professional routine of production engineers acting in different sectors; and important aspects of Mathematics in their profession that were not contemplated in the initial training of the production engineer. This research was subsidized by the Theory of Mathematics in the Context of Sciences (TMCC) and by the consequential stage of Dipcing, a drafting curricular methodology tied to it. As one of the research's results we highlight that according to the point of view of egresses, the Mathematics studied in Higher Education is not directly applied in their daily professional routines, but it did enable them the development of thinking skills beyond the scientifical, critical and analytical training and behavior, which benefits the confrontation of situations regarding different subjects that are mostly used in their daily professional routines and the development of a type of reasoning that can be used in all areas of practice.
\end{abstract}

Keywords: Production engineering. The role of mathematics in graduation. Egresses. Mobilization of mathematical knowledge. Daily professional routines. 